\title{
CANAL DE PEREIRA BARRETO: LOCAL DE TRANSIC ÃO ENTRE OS ARENITOS CAIUÁ, SANTO ANASTÁCIO E ADAMANTINA
}

\author{
Kenitiro SUGUIO $(*)$ \\ José Humberto BARCELOS( $(*)$ \\ Mario Gramani GUEDES( \\ Antonio Carlos VERDIANI(
}

\begin{abstract}
RESUMO
Na região Noroeste do Estado de São Paulo, encontra-se em construção o Canal de Pereira Barreto, que ligará os reservatórios das Usinas Hidroelétricas de Ilha Solteira (Rio Paraná) e Três Irmãos (Rio Tietê), esta, ainda em fase de obras.

Este canal corta arenitos cretácicos, cujas características de campo, observáveis em afloramentos da parte escavada até meados de 1984, permitem atribuí-los principalmente à Formação Santo Anastácio. São seguidos, com menor expressão, de arenitos das formações Caiuá e Adamantina, todos pertencentes ao Grupo Bauru, de idade cretácica. Eles se apresentam encimados por espessuras variáveis de manto de intemperismo, aqui denominados de solos residuais, que resultam do intemperismo dos arenitos e representam um evento pós-cretácico. Além disso, estão também presentes sedimentos coluviais seguidos de aluviais, que devem ser de idade cenozóica.

As análises granulométricas dos sedimentos vieram confirmar não somente a presença das unidades litológicas reconhecidas no campo, bem como os seus paleoambientes deposicionais essencialmente fluviais. A transição entre as unidades cretácicas parece ser gradual e provavelmente interdigitada, como têm sido admitida por diversos autores. Deste modo, os seus limites poderiam ser traçados somente de maneira mais ou menos arbitrária.

As camadas lenticulares de calcrete e os tipos de argilo-minerais presentes na Formação Santo Anastácio, quando analisados no contexto geológico em que se acham inseridos, ensejam a interpretação do paleoclima reinante durante a sua sedimentação, como quente e seco (semi-árido).
\end{abstract}

\section{ABSTRACT}

In northwestern region of the State of São Paulo there is being built the Pereira Barreto Channel, which will establish a linkage between the reservoirs of the Ilha Solteira (Paraná River) and Três Irmãos (Tietê River) water power plants, the lattest under construction.

This channel cuts Cretaceous sandstones, whose field characteristics could be observed on outcrops of the portion digged until about the middle of the last year, allowed us to assume that they mostly belong to Santo Anastácio Formation. It is followed in importance by the sandstones of Caiuá and Adamantina formations, all of them belonging to the Cretaceous Bauru Group. They are superimposed by a weathering mantle of variable thickness, here named residual soils, which represent post-Cretaceous weathering product of the sandstones. Moreover, there are also colluvial sediments followed by alluvial sediments, probably both Cenozoic.

The grain size analysis of these sediments have allowed us to confirm both the presence of the lithological units recognized during the field surveys, as well as their essentially fluvial sedimentary paleoenvironments. The transition between the Cretaceous units is gradual and probably intertonguing, as assumed by several authors. In this way, their limits could be outlined only more-or-less arbitrarily.

The lenticular calcrete beds and the clay mineralogy of the Santo Anastácio Formation, when interpreted in the geological context in which they are inserted, give an opportunity to interpret that during its sedimentation the paleoclimate must have been warm and dry (semi-arid).

(*) Instituto de Geociências, Universidade de São Paulo (USP). Caixa Postal 05508 — São Paulo, SP, Brasil

(**) Instituto de Geociências e Ciências Exatas, Universidade Estadual Paulista (UNESP). Caixa Postal 178 - Rio Claro, SP, Brasil

(***) Companhia Energética de São Paulo (CESP). Av. Paulista, 2.064 - São Paulo, SP, Brasil 


\section{INTRODUÇÃO}

As formacões Adamantina e Marilia do Grupo Bauru já foram alvos de exaustivos estudos sedimentológicos por vários autores (FREITAS, 1955; SUGLIO, 1973a; COIMBRA, 1976; SUGUIO et alii, 1977; BRANDT NETO, 1977 e 1984; BARCELOS, 1984, entre outros).

Bem menos estudadas nos seus pormenores, as formačoes Caiuá e Santo Anastácio têm também merecido alguns estudos. Deste modo, embora persistam algumas dissensões, principalmente no que concerne ao seu ambiente de sedimentação, a Formaçào Caiuá já foi estudada por diversos autores (BOSIO \& LANDIM, 1970/71; FREITAS, 1973 e ARID et alii 1981). Por outro lado, a ocorrência de uma fácies de transiçào entre Caiuá e as outras formacòes do Grupo Bauru já havia sido reconhecida por LANDIM \& SOARES em 1976. Porém, mesmo após a proposiçào formal da Formação Santo Anastácio por SOARES et alii (1980) e SUGUIO (1980), poucos estudos têm sido devotados aos seus aspectos sedimentológicos (ARID) et alii, 1981; SUGUIO \& BARCELOS, 1983a e BARCELOS, 1984).

A obra do Canal de Pereira Barreto, onde foram escavados até mais de $50 \mathrm{~m}$ de espessura de sedimentos, predominantemente da Formação Santo Anastácio, oferece uma oportunidade impar para estudo detalhado desta Formaçào e de alguns aspectos de passagem para formaçōes associadas.

\section{LOCAL DE ESTUDO}

\subsection{Situação geográfica}

O Canal de Pereira Barreto, quando concluido, deverá interligar os reservatórios das Usinas Hidroelétricas da tha Solteira no Rio Paraná e Três Irmãos no Rio Tietê (Fig. 1). Este canal, com 9km de extensâo, e taludes com 50 a $60 \mathrm{~m}$ de largura na base e $61 \mathrm{~m}$ de profundidade máxima, está sendo construído pela PORTOBRÁS (Empresa de Portos do Brasil S/A) e CESP (Companhia Energética de São Paulo).

O canal interligará o reservatório da Usina Hidroeletrica da Ilha Solteira com o reservatório do futuro aproveitamento múltiplo de Três Irmãos, em construção, que faz parte de um complexo de obras planejadas para fins de geracão energética e navegação do Baixo Tietê e do Rio Paraná.

\subsection{Situaçào geológica}

Os mapas geológicos mais recentes do Estado de São Paulo, como o do PROMINÉRIO (1981) e DAEE/UNESP (1982), respectivamente nas escalas $1: 500.000$ e $1: 250.000$, admitem a ocorrência de sedimentos da Formaçào Santo Anastácio na localidade estudada.

Por outro lado, a proximidade das calhas dos principais rios da regiào condiz também com a existência de cobertura cenozóica, principalmente de sedimentos aluviais.

\section{UNIDADES LITOLÓGICAS E CRITERIOS DE CAMPO PARA SUA DISTINC ÃO}

$\mathrm{Na}$ localidade estudada podem ser reconhecidas, a grosso modo, as seguintes unidades litológicas: arenitos cretácicos, solos residuais, sedimentos coluviais e sedimentos aluviais (Fig. 2a e 2b). No interior dos arenitos cretácicos e dos solos residuais ocorrem camadas lenticulares de argilito e calcrete nodular e em "forma de favo" (honeycomb).

$\mathrm{O}$ aspecto mais crítico na descriçào deste afloramento reside na distincào dos arenitos cretácicos. Alguns dos critérios que foram utilizados na diferenciação dos arenitos pertencentes às formações Caiuá, Santo Anastácio e Adamantina, aflorantes neste local de transiçào dessas unidades litoestratigráficas, foram os seguintes:

Formaçào Caiuá - Nesı́a formação ocorrem principalmente arenitos de granulação fina a média, de selecào moderada a boa (teor de pelitos $₹ 5 \%$ ), de cor predominante $5 \mathrm{RP} 4 / 2$ (purpura vermelho acinzentado). Outra feição típica desses arenitos é a presença de estratificações cruzadas, freqüentemente acana-

ladas, quase sempre de grande porte, embora possam ocorrer horizontes maciços ou com laminações horizontais plano-paralelas. Em alguns locais, ocorrem paleocanais preenchidos por sedimentos pelíticos e estruturas de deformaçào em estado hidroplástico (SOBREIRO NETO et alii, 1981). 
Formação Santo Anastácio - Caracterizada por arenitos de granulaçào em geral um pouco mais fina que a Caiuá, de seleção pobre a muito pobre (teor de pelitos entre 5 a $10 \%$ ), de cores predominantes entre $10 \mathrm{R} 5 / 4$ (vermelho moderado) a $10 \mathrm{R} 4 / 2$ (vermelho-acinzentado). São relativamente freqüentes fragmentos milimétricos dispersos de um material pulverulento e esbranqüiçado, muitas vezes atribuidos a silex intemperizado. As estratificações cruzadas sào de porte menor e de ocorrência mais localizada que na Formação Caiuá. As estratificações horizontais plano-paralelas são mais espessas e incipientemente definidas. São encontrados paleocanais preenchidos por sedimentos pelíticos com estruturas tubulares, lembrando bioturbações por organismos perfuradores, formadas penecontemporaneamente à sedimentação. Outra feição que parece ser mais característica da formaçào Santo Anastácio que da Formação Caiuá são as camadas e nódulos de calcrete, descritos anteriormente por SUGUIO \& BARCELOS (1983).

Formação Adamantina - Enquanto as formações Caiuá e Santo Anastácio são constituidas essencialmente de arenitos, a Formaçào Adamantina apresenta uma litologia bem mais diversificada, pois ocorrem siltitos, argilitos, lamitos e arenitos. Além disso, as cores são também muito variáveis, apresentando freqüentemente cores variegadas. Estruturas sedimentares primárias de vários tipos, tais como, marcas ondulares, gretas de contração, estratificações cruzadas, camadas convolutas, etc., ocorrem nesses sedimentos. As estratificações cruzadas encontradas nos niveis arenosos são tabulares ou tangenciais e de porte, em geral, pequeno a médio.

\section{AMOSTRAS ESTUDADAS}

Foi realizada uma amostragem específica para execução deste trabalho, quando foram coletadas 31 amostras referidas às diferentes unidades litológicas aflorantes (Fig. 3a e 3b). Dessas amostras, 25 foram analisadas quanto à composição granulométrica e teor de carbonato de cálcio (calcita). Tab. 1 .

Além disso, foram utilizados também os resultados de análises petrográficas, de teor de hidróxidos de ferro e de tipos de argilo-minerais, determinados pelo Instituto de Pesquisas Tecnológicas S.A., em 17 amostras provenientes da escavação experimental, retiradas do seu talude esquerdo, correspondendo aproximadamente à estaca 425 do canal (Fig. 3c). As observações de campo realizadas pelos autores deste trabalho permitiram atribuir essas amostras à Formação Santo Anastácio.

\section{ESTUDOS SEDIMENTOLÓGICOS}

\subsection{Distribuições granulométricas}

As 25 amostras coletadas pelos autores foram analisadas granulometricamente pelos métodos convencionais encontrados em SUGUIO (1973b).

Após o processamento gráfico dos resultados, os parâmetros foram obtidos através das fórmulas propostas por FOLK \& WARD (1957). Das várias combinações possiveis entre os diferentes parâmetros, dois a dois, chegou-se a conclusão de que as relações diâmetro médio $\left(\mathrm{M}_{\mathrm{Z}}\right)$ e freqüência de silte + argila $(\%)$ e diâmetro médio $(\mathrm{Mz})$ e desvio padrão $\left(\Gamma_{1}\right)$ são adequadas para discriminar os três arenitos cretácicos. Deste modo, os teores de silte + argila atingem os valores mais baixos e mais constantes na Formação Caiuá (Fig. 4a), enquanto que eles são progressivamente mais altos para as formaçōes Santo Anastácio e Adamantina, sucessivamente, distribuindose por intervalos mais amplos nestas duas unidades. Por outro lado, os valores de desvio padrão mostraram que os sedimentos da Formação Caiuá são moderadamente selecionados, enquanto que os da Formação Santo Anastácio variam de moderada a pobremente selecionados e os da Formaçâo Adamantina de moderada a pobre e muito pobremente selecionados (Fig. 4b).

Desta maneira, tanto as caracteristicas de campo, quanto os intervalos de variação de certos parâmetros granulométricos permitem, em termos relativos, discriminar razoavelmente as unidades litoestratigráficas presentes. Porém, è muito difícil delinear os contatos entre as unidades porque as passagens são graduais e esta é a razão porque não toram traçados os contatos entre os arenitos cretácicos aflorantes (Fig. 2a e 2b). 


\subsection{Diagrama de SAHU (1964)}

Condições semelhantes de energia e viscosidade podem ser encontradas em diferentes ambientes de sedimentação. Deste modo, as indicações de ambientes (eólico, praial, turbidez, fluvial e marinho raso) encontradas no diagrama de SAHU (op. cit.) devem ser encaradas apenas como alguns exemplos de ambientes, cujas condiçòes de energia e viscosidade encontrar-se-iam predominantemente naquelas condições.

Os pontos correspondentes aos três arenitos cretácicos, bem como aos sedimentos cenozóicos (coluviais e aluviais), foram lançados neste diagrama (Fig. 5). O grupo de amostras da Formação Caiuá indicou condiçōes hidrodinâmicas paleoambientais próximas às de um ambiente marinho raso, corroborando dados anteriores de ARID et alii (1981). Segundo BOSIO \& LANDIM (1970/1971), o ponto correspondente ao Caiuá acusaria condiçōes fluviais. De maneira análo$\mathrm{ga}$, os pontos correspondentes às formações Santo Anastácio e Adamantina mostraram condiçōes hidrodinâmicas paleoambientais tipicamente fluviais, perfeitamente de acordo com a idéia em voga entre os principais pesquisadores que vêm estudando o Grupo Bauru.

Os pontos correspondentes aos sedimentos cenozóicos também concordaram com a interpretaçào de campo, já que o ponto que representa os sedimentos coluviais sitou-se na "área de turbidez", pois estes sedimentos devem ter sido mobilizados por movimentos de massa (rastejo), enquanto que os sedimentos aluviais situavam-se na "área dos sedimentos fluviais"'.

\section{ESTUDOS PETROGRÁFICOS}

As 17 amostras submetidas à análise petrográfica expedita pelo Instituto de Pesquisas Tecnológicas S/A acusaram grande homogeneidade, tanto nas características mineralógicas quanto texturais (Tab. 2).

Entre as partículas clásticas predominam os grãos de quartzo ( 75 a $90 \%$ ), seguidas por fragmentos líticos $(5$ a $10 \%)$, minerais pesados $(0$ a $10 \%)$ e feldspatos $(0$ a $5 \%$ ). Fato que ressalta entre os componentes clásticos é a freqüência anormalmente alta de minerais pesados. A matriz é síltico-argilosa, cuja composi- çào em argilo-minerais foi também analisada. O cimento é constituído de carbonato de cálcio (calcita) e hidróxidos de ferro que, em conjunto, perfazem 0 a $10 \%$ da rocha. Os fragmentos líticos sào constituidos de rocha basáltica quase sempre alterada, folhelho, quartzito, siltito, arenito e sílex. Os principais minerais pesados são: limonita, opacos (magnetita e ilmenita?), turmalina, augita, zircão, granada, rutilo e estaurolita. Não foi feita distinção entre os feldspatos alcalinos e plagioclásios.

O grau de seleção e; em geral, baixo e mais raramente moderado a bom. $\mathrm{O}$ grau de arredondamento mostra que os grãos são sempre subangulosos e subarredondados. Na maior parte das vezes a granulação predominante é a areia fina $(0,250-0,125 \mathrm{~mm})$. As relações espaciais entre os grãos indicam contato pontual (predominante), côncavo-convexo e reto (comuns) e grãos "flutuantes" (raros).

As características composicionais dos arenitos analisados, levando-se em conta as freqüências relativas de quartzo, feldspato e fragmentos líticos, além do teor de matriz (diâmetro inferior a $0,030 \mathrm{~mm}$ ) permitem classificar todas as amostras analisadas como arenitos sublíticos (sublitharenites), utilizando-se a nomenclatura proposta por McBRIDE (1963). Esses arenitos constituem termos análogos de subarcósios, mas contendo mais fragmentos líticos que feldspatos. Os arenitos sublíticos contêm, de acordo com a definição, entre 65 e $95 \%$ de quartzo, 5 a $25 \%$ de fragmentos líticos e 0 a $10 \%$ de feldspatos.

\section{ANÁLISE DE ARGILO-MINERAIS}

A fração argilosa a ser submetida à difração de raios-X foi obtida por decantação. Os difratogramas foram conseguidos através de lâminas orientadas, no estado natural, após saturação com etileno-glicol e após aquecimento a $450^{\circ} \mathrm{C}$ durante duas horas.

Essas análises, efetuadas nas 17 amostras de escavação experimental, correspondentes à Formação Santo Anastácio, mostraram que estão presentes somente dois grupos de argilo-minerais: esmectica e ilita. A esmectita aparece em freqüências variáveis de 77 a 100\% (média de $90 \%$ ) e a ilita de 0 a $23 \%$ (média de $10 \%)$. 
As amostras PB-10 e PB-14, coletadas de lentes de argilito da Formação Santo Anastácio, indicaram também a presença dos mesmos argilo-minerais mencionados. Além disso, a pouca definição dos picos correspondentes a esses minerais no difratograma sugere que os argilo-minerais apresentam-se com grau de cristalinidade muito baixo.

\section{COMPOSIÇÃO DO CIMENTO}

Os materiais que cimentam as rochas sedimentares cretácicas, predominantemente arenosas, do Grupo Bauru, na região estudada, são constituídos de calcita, hidróxidos de ferro e, em menor grau, quartzo com crescimento secundário (overgrowth) e argilo-minerais autigênicos (recristalizados). Os teores de materiais cimentantes, de acordo com as análises petrográficas do Instituto de Pesquisas Tecnológicas S.A., variam de 0 a $10 \%$.

Os teores de hidróxidos de ferro, determinados através de ensaios químicos utilizando-se ditionito de sódio em meio cítrico, nas 17 amostras da escavação experimental, variaram de 0,23 a $4,92 \%$ (média de $2,93 \%$ ), conforme se vê na Tab. 1 .

Os teores de carbonato de cálcio (calcita), determinados por ataque em ácido clorídrico, mostraram valores inferiores a $1 \%$ para as amostras PB-1 a PB-29, mas as amostras PB-30 e PB-31, representando lentes de argilito muito calcíferas, forneceram teores de cerca de $30 \%$ a $40 \%$, respectivamente. Neste caso, o teor alto de calcita se deve ao material recristalizado em forma de veios que recortam densamente o argilito. Certamente, os teores de $\mathrm{CaCO}_{3}$ devem ser até superiores a $50 \%$ nos nódulos de calcretes, como foi verificado por SUGUIO et alii (1975) em outras formações do Grupo Bauru.

\section{ESTRATIFICAÇÕES CRUZADAS}

Em alguns trechos do canal, particularmente nas porções inferiores dos cortes, afloram arenitos cujas características macroscópicas são muito semelhantes às da Formação Santo Anastácio, porém são portadores de conspícuas estra- tificações cruzadas de grande porte. Esses arenitos foram considerados como pertencentes à Formação Caiuá.

As estratificações cruzadas chegam a apresentar seqüências com espessura superior a $10 \mathrm{~m}$ e as camadas frontais têm dezenas de metros de comprimento. A maioria pode ser classificada como do tipo acanalado.

As atitudes dessas estratificações cruzadas foram medidas detalhadamente no corte da margem direita do canal, no trecho compreendido entre as estacas $328 \mathrm{e}$ 357 (Fig. 2), porque formam superfícies de descontinuidade importantes na avaliação da estabilidade dos taludes estabelecidos nos arenitos. Os valores médios de 241 medidas realizadas indicaram rumos de mergulho das camadas frontais variáveis entre 288 e $335^{\circ}$ (quadrante $\mathrm{NW}$ ) e mergulho médio de $20^{\circ}$. Isto sugere que neste local as paleocorrentes deposicionais estavam dirigidas para $o$ quadrante NW.

É provável que alguns dos planos medidos correspondam a fraturas e não estratificações, porém estes casos devem ser raros, pois se constata que na área de Rosana (SP), por exemplo, próximo à Usina Hidroelétrica de Porto Primavera (em construção), as fraturas são em geral verticais a subverticais e facilmente distinguíveis das estratificações cruzadas propriamente ditas.

\section{CONSIDERAÇÕES FINAIS}

Mesmo em região de transição, como é o caso do local de construção do Canal de Pereira Barreto, onde estão presentes três das formações do Grupo Bauru, é ainda possível distinguir, tanto no campo quanto em laboratório, as diferentes unidades litoestratigráficas.

A distribuição granulométrica, bem como as estruturas sedimentares presentes sugerem paleoambientes de sedimentação essencialmente subaquáticos fluviais para os arenitos cretácicos presentes.

A natureza petrográfica dos arenitos, essencialmente sublítica somada às características texturais e aos tipos de argilo-minerais (predominância absoluta do grupo da esmectita), além da ocorrência de camadas lenticulares de calcrete é fortemente indicativa de paleoclima 
quente e seco (semi-árido) durante a sedimentação da Formação Santo Anastácio, conforme já foi sugerido por SUGUIO (1980) e SUGUIO \& BARCELOS (1983b).

Acima dos arenitos cretácicos ocorre um manto de intemperismo, que constitui os solos residuais desses arenitos, cuja formação, tendo-se iniciado em época pós-cretácica deve continuar até os nossos dias.

Os sedimentos coluviais e aluviais, superpostos aos solos residuais, representando prováveis fases de sedimentação cenozóica, talvez sejam correlacionáveis aos terraços colúvio-aluviais identificados anteriormente por SUGUIO et alii (1984) na região do Pontal do Paranapanema.

\section{AGRADECIMENTOS}

Os autores agradecem à CESP (Companhia Energética de São Paulo) pelo apoio logístico para a realização dos trabalhos de campo, bem como pelo acesso e liberação de todos os dados geológicos relativos à construção do Canal de Pereira Barreto.

Parâmetros granulométricos

\begin{tabular}{cccccccc}
\hline Amostra & Unidade & Mz(0) & $\tau l$ & $\mathrm{SK}_{1}$ & $\mathrm{~K}_{\mathrm{i}}$ & $\begin{array}{c}\text { Teor de } \\
\mathrm{CaCO}_{3}(\%)\end{array}$ & $\begin{array}{c}\text { Silte }+ \\
\text { Argila }(\%)\end{array}$ \\
\hline 1 & ADM & 2,64 & 1,54 & 0,52 & 2,46 & 0,97 & 11,50 \\
2 & ADM & 2,46 & 1,51 & 0,22 & 2,80 & 0,97 & 11,56 \\
3 & ADM & 4,05 & 2,21 & 0,58 & 1,55 & 0,98 & 27,54 \\
4 & ADM & 3,16 & 1,53 & 0,34 & 2,16 & 0,97 & 18,01 \\
5 & ADM & 3,93 & 2,19 & 0,64 & 1,90 & 0,98 & 21,42 \\
6 & ADM & 2,98 & 0,93 & 0,07 & 1,28 & 0,98 & 10,18 \\
7 & SAN & 3,59 & 1,20 & 0,10 & 1,56 & 0,97 & 22,44 \\
8 & SAN & 4,16 & 1,99 & 0,46 & 1,69 & 0,98 & 27,11 \\
9 & SAN & 2,73 & 1,32 & 0,35 & 2,97 & 0,97 & 11,52 \\
11 & SAN & 2,95 & 0,94 & 0,27 & 1,61 & 0,96 & 10,08 \\
12 & SAN & 2,83 & 1,48 & 0,29 & 3,17 & 0,98 & 10,43 \\
13 & COL & 4,80 & 2,53 & 0,59 & 0,54 & 0,97 & 35,66 \\
15 & SAN & 3,12 & 0,94 & 0,10 & 1,00 & 0,96 & 15,74 \\
16 & SAN & 2,93 & 0,99 & 0,01 & 0,90 & 0,99 & 9,32 \\
18 & SAN & 2,77 & 1,07 & 0,09 & 0,90 & 0,97 & 10,01 \\
19 & SAN & 3,07 & 1,38 & 0,22 & 1,41 & 0,98 & 17,63 \\
20 & CAI & 2,34 & 0,96 & 0,19 & 1,14 & 0,99 & 6,07 \\
22 & SAN & 2,67 & 0,80 & 0,03 & 1,05 & 0,97 & 5,16 \\
23 & CAI & 2,50 & 0,61 & $-0,28$ & 2,29 & 0,97 & 3,50 \\
24 & CAI & 2,34 & 0,58 & 0,19 & 1,31 & 0,98 & 3,02 \\
25 & CAI & 2,70 & 0,93 & 0,15 & 1,24 & 0,97 & 8,21 \\
26 & SAN & 2,75 & 1,00 & $-0,02$ & 1,15 & 0,98 & 5,23 \\
27 & ALU & 4,26 & 2,50 & 0,64 & 1,21 & 0,97 & 14,21 \\
28 & COL & 4,58 & 2,58 & 0,58 & 1,38 & 0,96 & 29,51 \\
29 & COL & 4,76 & 2,56 & 0,47 & 0,66 & 0,97 & 40,23
\end{tabular}

Tabela 1 - Parâmetros granulométricos segundo FOLK \& WARD (1957) e teores de CaCO $\mathrm{Cas}_{3}$ amostras analisadas do Canal de Pereira Barreto.

CAI (Formação Caiuá), SAN (Formação Santo Anastácio),

ADM (Formação Adamantina), ALU (Sedimentos aluviais), COL (Sedimentos coluviais). 


\begin{tabular}{|c|c|c|c|c|c|c|c|c|c|c|}
\hline Amostra & Clastos & Quartzo & Liticos & Feldspatos & M. pesados & $\begin{array}{l}\text { Cimento + } \\
\text { Matr. arg. }\end{array}$ & $\begin{array}{l}\text { Matriz } \\
\text { siltica }\end{array}$ & $\begin{array}{c}\text { Teor de } \\
\text { Hidr. de Fe }\end{array}$ & Esmectita & Ilita \\
\hline Superf. & $95 \%$ & $75-80 \%$ & $10 \%$ & $5 \%$ & $5-10 \%$ & $0-5 \%$ & $0-5 \%$ & $0,23-1,95 \%$ & 94 & 6 \\
\hline 2911 & $90-95$ & $85-90$ & $5-10$ & $0-5$ & $0-5$ & $0-5$ & 5 & 2,07 & 86 & 14 \\
\hline 2912 & $95-100$ & 85 & $5-10$ & $0-5$ & 5 & $0-5$ & traços & 1,29 & 85 & 15 \\
\hline 2913 & $90-95$ & 80 & $5-10$ & 5 & $5-10$ & $0-5$ & 5 & 2,04 & 93 & 7 \\
\hline 2914 & 100 & 85 & $5-10$ & 5 & $0-5$ & traços & traços & 1,22 & 88 & 12 \\
\hline 2915 & 95 & $85-90$ & $5-10$ & $0-5$ & $0-5$ & $0-5$ & $0-5$ & 1,33 & 90 & 10 \\
\hline superf. & 90 & 75 & 10 & 5 & 10 & 5 & 5 & $4,34-4,92$ & 100 & - \\
\hline 2916 & 85 & 80 & $5-10$ & 5 & $5-10$ & $5-10$ & $5-10$ & 4,54 & 86 & 14 \\
\hline 2917 & $90-95$ & $75-80$ & 10 & 5 & $5-10$ & 5 & $0-5$ & 4,01 & 77 & 23 \\
\hline 2918 & $90-95$ & $80-85$ & 10 & $0-5$ & 5 & 5 & $0-5$ & 4,22 & 85 & 15 \\
\hline 2919 & 90 & 80 & $5-10$ & 5 & $5-10$ & 5 & 5 & 3,78 & 88 & 12 \\
\hline 2920 & $85-90$ & 80 & $5-10$ & 5 & $5-10$ & $5-10$ & 5 & 4,35 & 87 & 13 \\
\hline 2921 & 95 & 80 & $5-10$ & 5 & $5-10$ & $0-5$ & $0-5$ & 3,19 & 93 & 7 \\
\hline 2922 & $90-95$ & $75-80$ & 10 & 5 & $5-10$ & $0-5$ & 5 & 3,70 & 97 & 3 \\
\hline 2923 & $85-90$ & $75-80$ & 10 & 5 & $5-10$ & 5 & $5-10$ & 3,67 & 92 & 8 \\
\hline 2924 & 90 & $75-80$ & 10 & 5 & $5-10$ & 5 & 5 & 3,37 & 92 & 8 \\
\hline 2925 & $85-90$ & 75 & 10 & 5 & 10 & $5-10$ & 5 & 3,29 & 91 & 9 \\
\hline
\end{tabular}

Tabela 2 - Resultados de análises petrográficas expeditas de amostras da Formação Santo Anastácio, coletadas na escavação experiméntal do Canal de Pe reira Barreto, executadas pelo Instituto de Pesquisas Tecnológicas S.A. 


\section{—Três Irmãos}

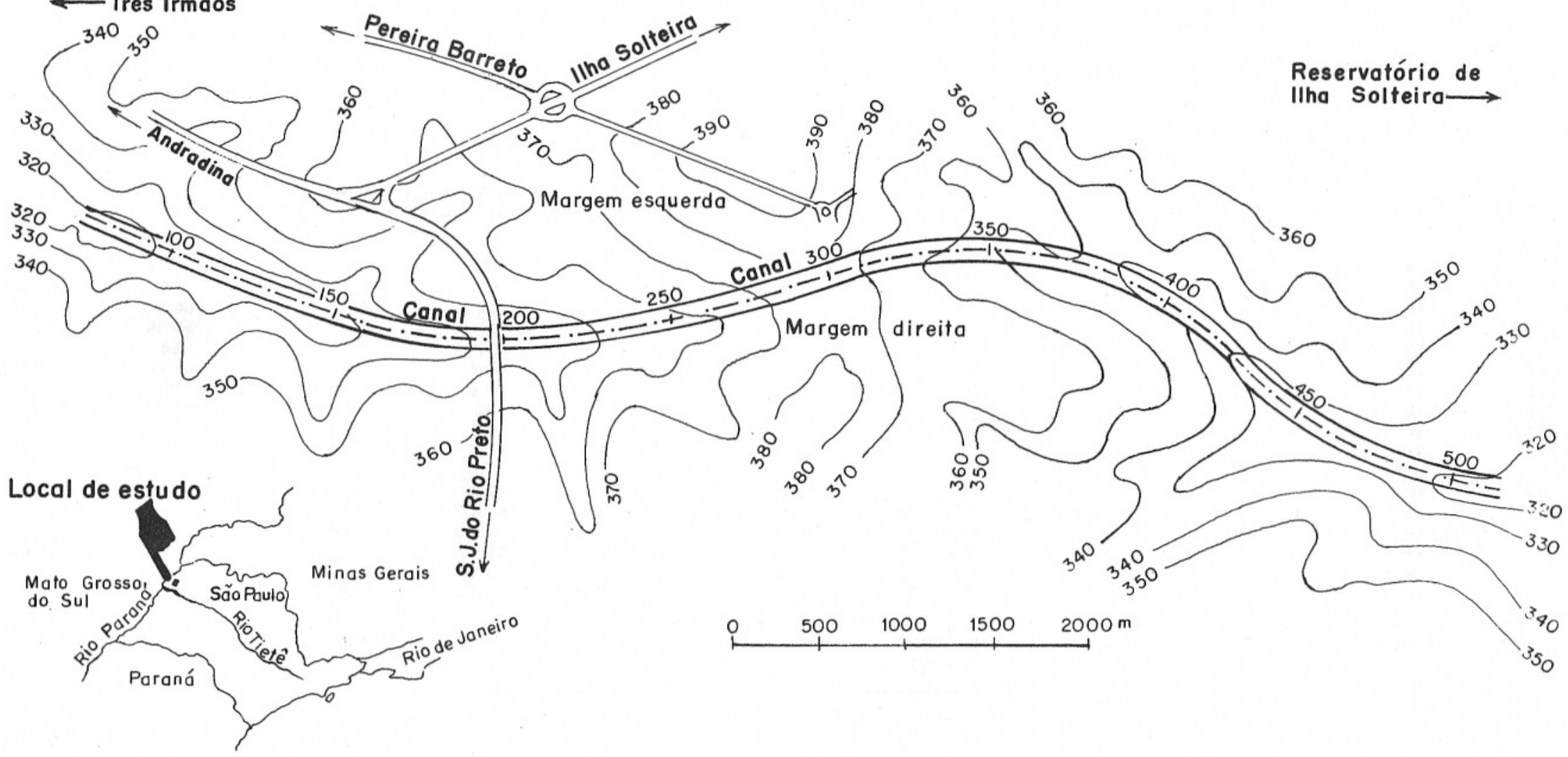




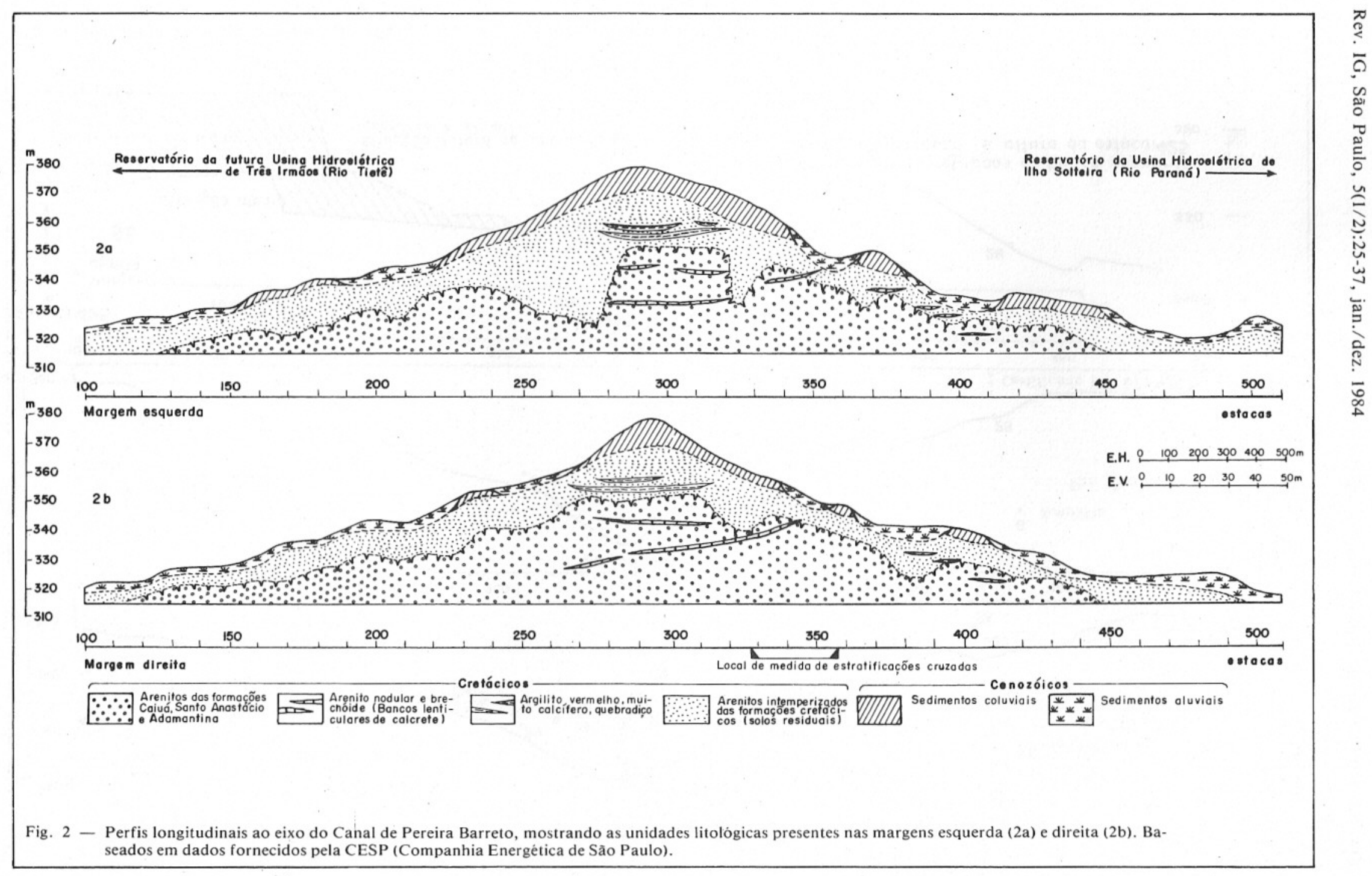




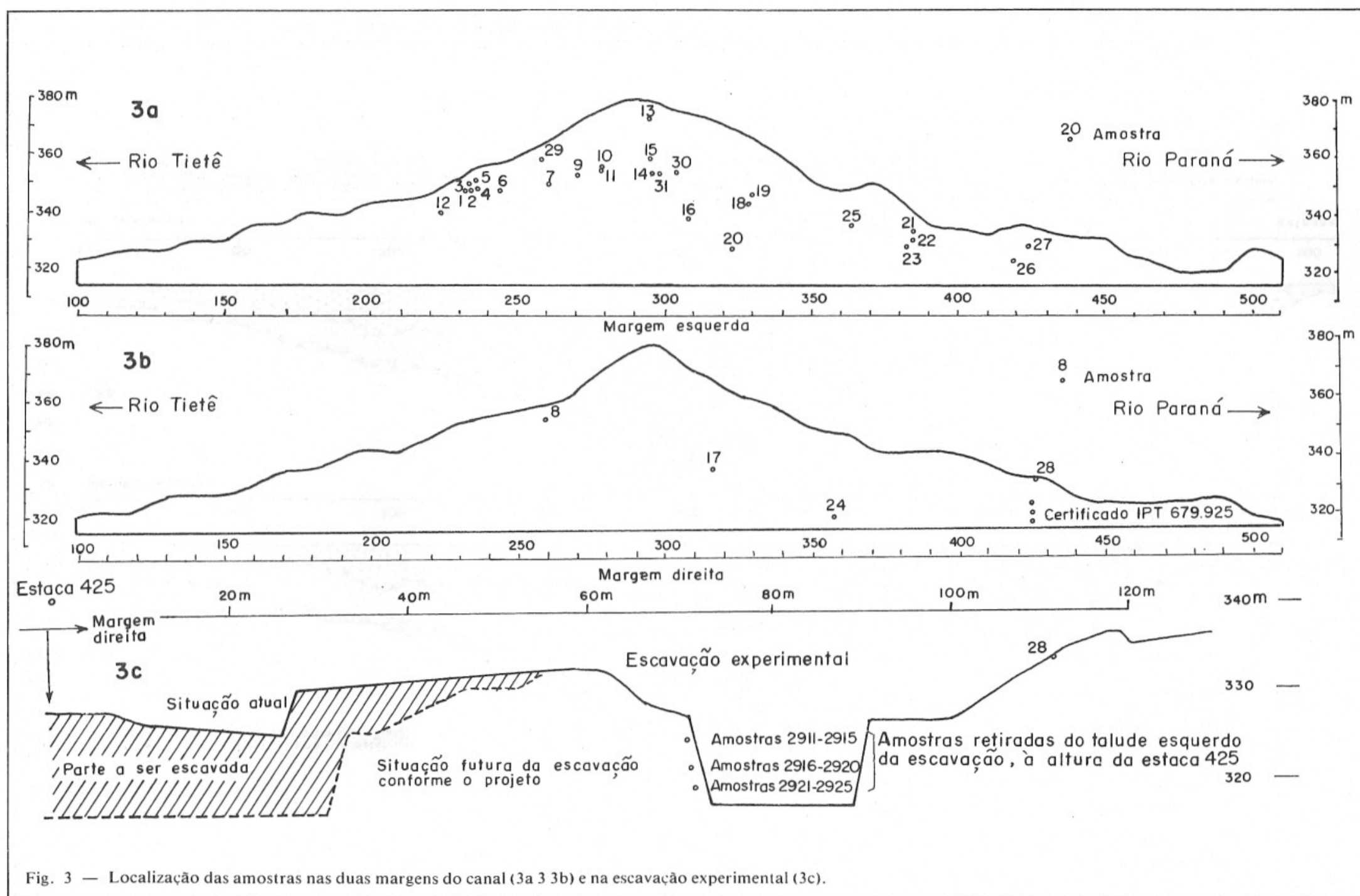




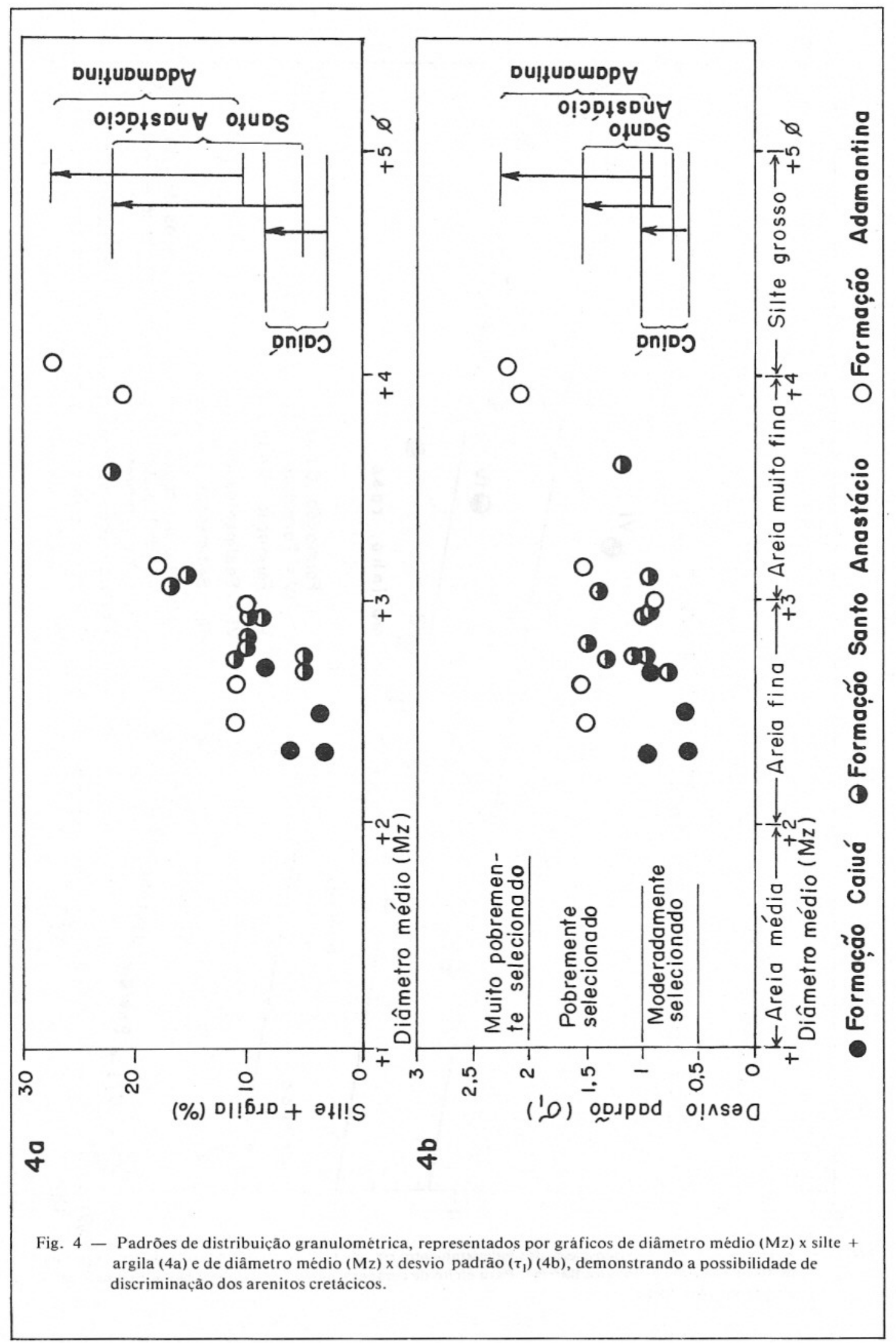




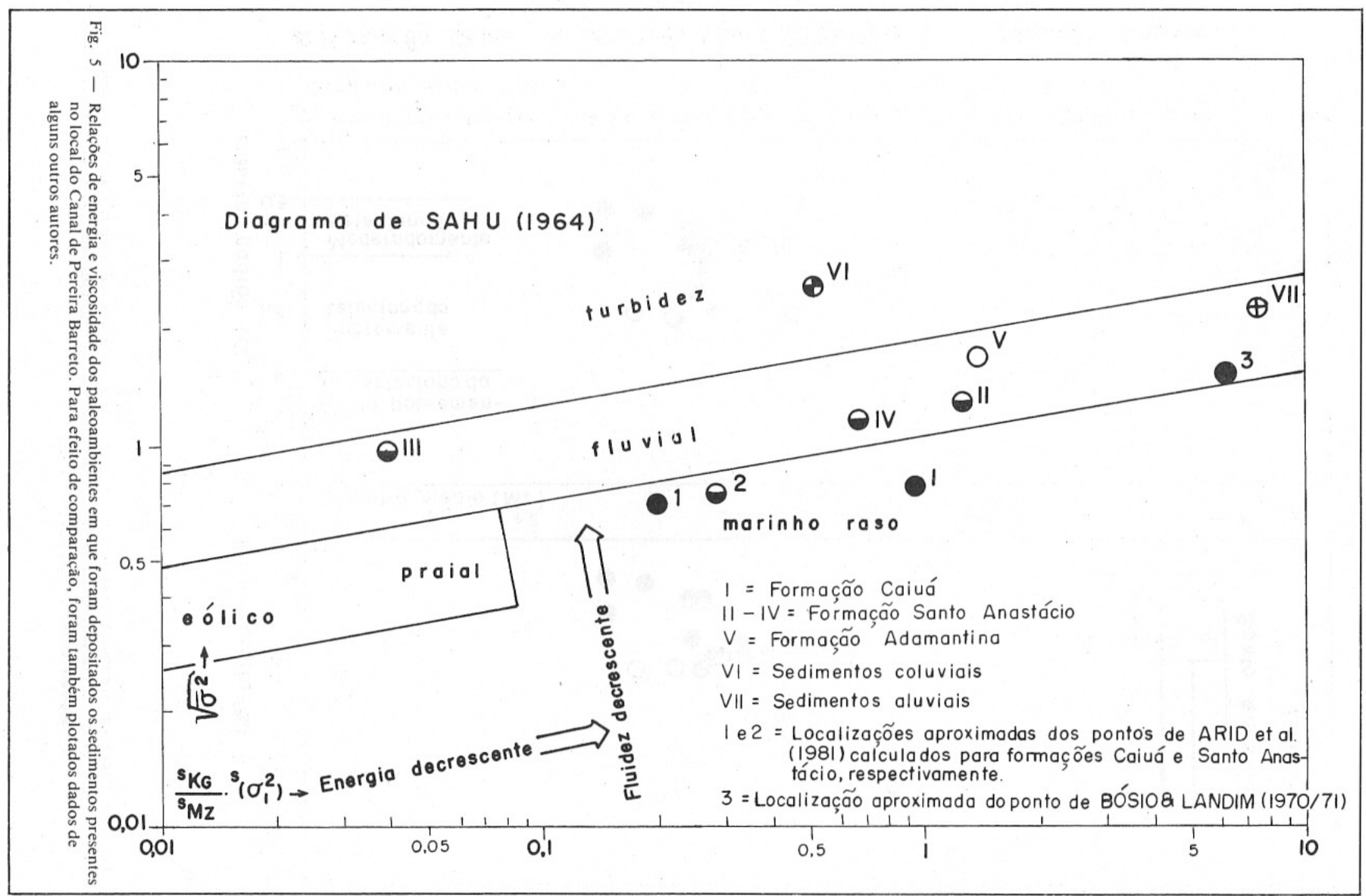




\section{REFERÊNCIAS BIBLIOGRÁFICAS}

ARID, F.M. et alii 1981 Contribuição ao estudo da Formação Caiuá. Revista IG, São Paulo, 2(1): 5-20.

BARCELOS, J.H. 1984 Reconstrução paleogeográfica de sedimentação do Grupo Bauru baseada na sua redefinição estratigráfica parcial em território paulista e no estudo preliminar fora do Estado de São Paulo. Rio Claro, UNESP. 190p. (Tese de Livre Docência)

BÓSIO, N.J. \& LANDIM, P.M.B. 1970/1971 Um estudo sedimentológico sobre a Formação Caiuá. Boletim Paranaense de Geociências, Curitiba, (28/29): 145-157.

BRANDT NETO, M. 1977 Estratigrafia da Formação Bauru na região do Baixo Tietê. São Paulo, Universidade, Instituto de Geociências. 74p. (Dissertação de Mestrado).

1984 O Grupo Bauru na região centro-norte do Estado de São Paulo. São Paulo, Universidade, Instituto de Geociências. 106p. il. (Tese de doutoramento)

COIMBRA, A.M. 1976 Arenitos da Formação Bauru: estudo de áreas fontes. São Paulo, Universidade, Instituto de Geociências. 60p. il. (Dissertação de mestrado)

FOLK, R.L. \& WARD, W.C. 1957 Brazos river bar, a study in the significance of grain size parameters. Journal of Sedimentary Petrology, Tulsa, Oklahoma, 27(1): 3-26.

FREITAS, R.O. de 1955 Sedimentação, estratigrafia e tectônica da Série Bauru, Estado de São Paulo. São Paulo, Universidade, FFCL. 185p. (Boletim, 194 - Geologia, 14)

1973 Geologia e petrologia da Formação Caiuá no Estado de São Paulo. São Paulo, Instituto Geográfico e Geológico. 122p. (Boletim, 50)

l ANDIM, P.M.B. \& SOARES, P.C. 1976 Estratigrafia da Formação Caiuá. In: CJNGRESSO BRASILEIRO DE GEOLOGIA, 29. , Ouro Preto. Anais. Belo Horizonte, Sociedade Brasileira de Geologia. v.2 p. 195206.

McBRIDE, E.F. 1963 A classification of common sandstones. Journal of Sedimentary Petrology, Tulsa Oklahoma, 33:664-669.

PROGRAMA DE DESENVOLVIMENTO DE RECURSOS MINERAIS 1981 Mapa genlógico do Estado de São Paulo. São Paulo, PROMOCF T/SICCT. Escala 1:5\% .0r0.

SAHU, B.K. 1964 Depositional mechanism from size analysis of clastic sediments. Journal of Sedimentary Petrology, Tulsa Oklaho$\mathrm{ma}, 34: 73-83$.

SÃO PAULO. DAEE. 1982-1984 Mapa geológico do Estado de São Paulo. Rio Claro,
UNESP, - Instituto de Geociências e Ciências Exatas. 11 folhas.

SOARES, P.C. et alii 1980 Ensaio de caracterização estratigráfica do Cretáceo do Estado de São Paulo: Grupo Bauru. Revista Brasileira de Geociências, São Paulo, 10(3): 177 185.

SOBREIRO NETO, A.F. et alii 1981 Estruturas sedimentares primárias de ambiente flúviodeltaico da Formação Caiuá. In: SIMPĆSIO REGIONAL DE GEOLOGIA, $3 .^{\circ}$, Curitiba. Atas. São Paulo, Sociedade Brasileira de Geologia. v.2 p. 60-69.

SUGUIO, K. 1973a Formação Bauru: calcários e sedimentos detriticos associados. São Paulo, Universidade, Instituto de Geociências. 2vols. (Tese de Livre Docência).

1973b Introdução à sedimentologia. São Paulo, Ed. Edgard Blucher, EDUSP. 317p.

1980 Fatores paleoambientais e paleoclimáticos e subdivisão estratigráfica do Grupo Bauru. In: MESA REDONDA SOBRE A FORMAÇÃO BAURU NO ESTADO DE SÃO PAULO E REGIÕES ADJACENTES. São Paulo, Sociedade Brasileira de Geologia. Núcleo de São Paulo. p. 15-30. (Publicação especial, 7)

\& BARCELOS, J.H. 1983a Significado paleoambiental de estrutura "boudinóide" e outras feições presentes na seçãotipo da Formação Santo Anastácio do Grupo Bauru, Estado de São Paulo. Boletim IG, São Paulo, 14:49-54.

— \& 1983b Paleoclimatic evidence from the Bauru Group, Cretacenus of the Paraná Basin, Brazil. Revișta Brasileira de Geociências, São Paulo, 13(4): 232-236.

- et alii 1975 Composição química isotópica dos calcários e ambiente de sedimentação da Formação Bauru. Boletim IG, São Paulo, 6:55-75.

et alii 1977 Comportamentos estratigráficos e estrutural da Formação Bauru nas regiōes administrativas 7 (Bauru), 8 (São José do Rio Preto) e 9 (Araçatuba) no Estado de São Paulo. In: SIMPÓSIO REGIONAL DE GEOLOGIA, $1 .^{\circ}$, São Paulo. Atas. São Paulo, Sociedade Brasileira de Geologia. V.1, p. 231-247.

- et alii 1984 Quaternário do Rio Paraná em Pontal do Paranapanema: proposta de um modelo de sedimentação. In: CONGRESSO BRASILEIRO DE GEOLOGIA, $33 .^{\circ}$, Rio de Janeiro. Anais. São Paulo, Sociedade Brasileira de Geologia. v. 1 p. 10-18. 